\title{
Impact of Personal Factors on Environmental Education in Tertiary Institutions in Ekiti State, Nigeria
}

\author{
Comfort Olufunke Akomolafe \\ Department of Educational Foundations \& Management, \\ University of Ado-Ekiti, Nigeria
}

\begin{abstract}
This study examined the personal factors of individual students that could enhance environmental education in tertiary institutions. A total of 539 students of tertiary institutions were sampled, using multi-stage, simple random and purposive sampling techniques. The research was a descriptive design. Data were gathered using self-constructed questionnaire. Six research hypotheses were generated, t-test analysis was used to test hypotheses one and two, Analysis of variance(ANOVA) was used to test hypotheses three to five, while Pearson Product moment correlation method was use to test hypothesis six. The hypotheses were tested and the results were found to be significant at 0.05 level.

The study revealed that gender of students and parents' level of education, were not important factors in students' environmental awareness knowledge. Gender of students and parents' level of education were not important factors in their environmental attitude. The study further revealed that type of institution has no influence on students' environmental awareness knowledge, and also on their environmental attitude. However a significant relationship was established between students' environmental awareness knowledge and environmental attitude. Based on these findings, it was recommended that environmental education should be intensified in tertiary institutions and that its content should reflect the immediate needs of the students.
\end{abstract}

\section{Introduction}

Environmental education desires much attention, due to the environmental challenges that are facing the society, most especially the developing nations. Education seems to be the major tool to combat environmental degradation, climatic challenges, flooding, and indiscriminate dumping of refuse, poor knowledge of refuse disposal, unhygienic living, and unkempt environment. Environmental education is the acquisition of knowledge of how man can manage environment to bring out comfort, healthy and worthwhile living. It is also about the study of environmental challenges. It is to prevent human factors that constitute environmental challenges, and to have awareness of the challenges to be surmounted, and however to make environment habitable for people' survival, and comfort.

Environmental Education is a process in which individuals gain awareness of their environment, acquire knowledge, skills, values, experiences, and also the determination and enablement to act individually and collectively, to solve present and future environmental problems (Environmental Education n.d). Strapp et al [14] was of the view that environmental education is aimed at producing a citizenry that is knowledgeable concerning the biophysical environment and its associated problems, awareness of how to help solve these problems and motivation to work toward their solution.

Akomolafe [1] researched into students' awareness knowledge and attitude, revealed a high level of students' environmental awareness knowledge in the area of environmental hazard, flooding, global warming, and environmental change, destruction to forest, oil spillage, and indiscriminate bush and refuse burning. She concluded from her findings that, the high level of environmental awareness knowledge and favourable environmental attitude revealed in her study, was an indication of the level of preparedness, for parents of tomorrow who could have a better understanding of the environment, develop culture of environmental maintenance, and transfer same to younger generation.

A series of studies have been carried out on environmental education awareness and attitude, for instance Olawepo and Jekayinfa [9] revealed that teachers' attitudes and practices concerning environmental issues were not significantly influenced by gender and year of study, but area of specialization has a significant influence on both attitudes and behaviour. Ben Elia [3] found that 
education, income and age, were important influences on students' and people's perception of environmental issues. A study carried out by Gambro and Switzky [5] suggested that gender is an influential factor in gaining environmental knowledge. According to them, the number of science classes taken by students factored into the differences in knowledge between gender, but did not account for the entire difference. Gambro and Switzky [5] in their study revealed that out of a group of high school students questioned about energy and pollution issues, $29.2 \%$ of female had satisfactory knowledge as compared with almost $44 \%$ male students. Some studies, however, insisted that there were no significant differences between the gender in terms of science and environmental education. They further said that, one study about influential factors of learning environment, showed that gender was not one of the top three factors related to attitudinal outcomes (Henderson, Fisher, Fraser ) [7].

Series of studies in environmental education have revealed paying attention to pre-service teachers and environmental attitude. Peer, Goldman and Yavetz [11] reported limited environmental knowledge among pre-service teachers from three higher education institutions; however their overall environmental attitudes were positive. Furthermore, they observed a correlation between environmental knowledge and environmental attitudes. Arcury's[2] views that "increased knowledge about the environment is assumed to change environmental attitudes”. Stern [12] pointed out that historically human environment impact is connected to a variety of human necessities and desires; he cited for instance the "desire for physical comfort, mobility, relief from labour, enjoyment, power, status, personal security, maintenance of tradition and family, and so forth. Kaplan [8] referred to possible failures one could encounter when fostering environmentally responsive behaviours. He pointed out that instead of telling students what to do in regard to proenvironmental attitudes, a more responsive approach should emphasize culturally responsive ecological actions. In his view, this approach would take into account local variants such as culture, needs and motivation of local residents as members of the team in charge of addressing the problem.

A robust body of literature has been dedicated to the exploration of pro-environmental attitudes. Stern and Dietz [13] investigated this issue from person's value system framework. In their view the development of environmental-oriented behaviour depends on the value system people assign to themselves, to others and to fauna and flora resources. Similarly Wesley-Shultz [15] suggested that environmental concerns are formed only when people see themselves as an integral part of nature. Hartig, Kaiser and Bowler [6] stated that lack of favourable attitude was the result of individualistic postures adopted as people put themselves first over communal and environmental goals. Welch found out that education had a significant influence on environmental attitude. The study carried out by Pooley and O'connor (n-d) [10], investigated the cognitive and affective bases of environmental attitudes to indicate that, it is what people feel and believe about the environment that determines their attitudes toward it. The findings suggested that for environmental educators interested in changing environmental attitudes, emotions and beliefs rather than knowledge need to be targeted as sources of information on which to base their environmental programmes.

Observations have shown that, the keeping of environment clean and neat is deteriorating. Based on the experience of our old parents' who lived in remote villages, clans and compounds. They have the culture of keeping their environment clean, even with little or no knowledge of western education. In African setting women have been saddled with house hold cleaning and environmental sanitation, therefore women are supposed to be more knowledgeable and have positive attitude to environmental attitude. It is believed that with the level of education there should be improvement in the knowledge and attitude to environmental issues. It appears that with increase in population and urbanization, the level of keeping environment in hygienic condition is becoming deteriorating. Observations have been made concerning the level of education of parents of school pupils and students, seems to increase relative to parents of older generation. Mothers' level of education appears to be improving. Environmental challenges seem to receive the attention of various categories of educational institutions regardless of their level and specialization. It is apparent that the need for more knowledge about environmental education and efforts to bring improvement to our environment necessitated much research along the line of probable factors that could enhance the knowledge of environmental education. It seems personal factors as: gender, parents' education, type of institution could have any impact on students' knowledge of environmental education.

The purpose of this study was to investigate the factors that could enhance the environmental awareness knowledge and the attitude of students in tertiary institutions. Specifically, it was to examine the impact of gender, parents' education, and type of institution on students' environmental education. It was also to examine the relationship between 
environmental awareness knowledge and environmental attitude.

\section{Research Hypotheses}

The following research hypotheses were proposed for this study.

- There is no significant difference in students' environmental awareness knowledge and their gender.

- There is no significant difference in students' environmental attitude and their gender.

- Parents' level of education will not significantly influence their environmental awareness knowledge.

- Type of Institutions will not significant influence students' environmental awareness knowledge.

- Type of Institutions will not significant influence students' environmental attitude.

- There is no significant relationship between students' environmental awareness knowledge and their environmental attitude.

\section{Methods}

The population for this study consisted of students of tertiary institutions: University of AdoEkiti, College of Education and Federal Polytechnic. Multi-stage, purposive, and simple random sampling techniques were used to select students from various institutions and departments; science, social science, Arts, Education, and technology. A total number of 600 students were sampled; three hundred from the University, while one hundred and fifty were sampled each from both College of Education and Polytechnic. However, 539 subjects responded to the questionnaire.

A self-constructed questionnaire was employed to gather data for the study. The questionnaire was titled: Environmental awareness knowledge and students' attitude (EAKSA). The questionnaire was divided into three sections. Section A Sought information from personal data, patents' level of education, course of study and respondents' gender. Section B contained 10 items generated, all weighted on a 4-point Likert scale, which elicited information on environmental awareness knowledge of respondents. Section C also contained 10 items generated, all weighted on a 4-point Likert scale, elicited information on environmental attitude of respondents.

The data collected were analysed using t-test statistical method for hypotheses one and two. Oneway Analysis of variance (ANOVA) was used to analyse hypotheses three to five, while Pearson product moment correlation method was used to analyse hypothesis six. The hypotheses were all tested at 0.05 level of significance.

\section{Results}

Hypothesis One: There is no significant difference in students' environmental awareness knowledge and their gender.

Table 1. t-test Analysis on difference in students' environmental awareness knowledge and their gender.

\begin{tabular}{|l|l|l|l|l|l|l|}
\hline & $\mathrm{N}$ & Mean & SD & df & t-cal & $\begin{array}{l}\text { Table } \\
\text { value }\end{array}$ \\
\hline Male & 283 & 30.8233 & 7.76909 & & & \\
\hline Female & 256 & 30.2969 & 7.67870 & 537 & .790 & 1.96 \\
\hline
\end{tabular}

The hypothesis one was tested using t-test statistical method (see table 1), t-calculated value was lesser than the table value; the result was not significant at 0.05 . The hypothesis was accepted. Therefore gender of students was not important in their environmental awareness knowledge. In other words whether the students are male or female, their environmental awareness knowledge are not different.

Hypothesis two: There is no significant difference in students' environmental attitude and their gender.

Table 2. t-test Analysis on difference in students' environmental attitude and their gender

\begin{tabular}{|l|l|l|l|l|l|l|}
\hline & N & Mean & SD & df & $\begin{array}{l}\text { t- } \\
\text { cal }\end{array}$ & $\begin{array}{l}\text { Table } \\
\text { value }\end{array}$ \\
\hline Male & 283 & 30.0071 & 9.45763 & & & \\
\hline Female & 256 & 30.0781 & 9.18277 & 537 & .088 & 1.96 \\
\hline
\end{tabular}

Hypothesis two was tested using t-test statistical method (See Table 2). The calculated value was lesser than the table value. The result was therefore not significant at 0.05 . Hence, environmental attitude of students was not influenced by their gender.

Hypothesis three: Patents' level of education will not significantly influence students' environmental awareness knowledge. 
Table 3. ANOVA table on parents' Level of education and students' awareness knowledge

\begin{tabular}{|l|l|l|l|l|l|}
\hline Source & $\begin{array}{l}\text { Sums of } \\
\text { Square }\end{array}$ & df & $\begin{array}{l}\text { Mean } \\
\text { Square }\end{array}$ & $\begin{array}{l}\text { F- } \\
\text { ratio }\end{array}$ & $\begin{array}{l}\text { Table } \\
\text { Value }\end{array}$ \\
\hline $\begin{array}{l}\text { Between } \\
\text { groups }\end{array}$ & 14.856 & 5 & 2.971 & & \\
$\begin{array}{l}\text { Within } \\
\text { groups }\end{array}$ & 1021.530 & 533 & 1.917 & 1.550 & 2.21 \\
\hline Total & 1036.386 & 538 & & & \\
\hline
\end{tabular}

Hypothesis three was tested using one-way Analysis of variance (see table 3). The F-calculated was lesser than the table value. The result was not significant at 0.05 . The hypothesis was accepted. Therefore parents' level of education will not significantly influence students' environmental awareness knowledge. Students' environmental awareness knowledge was not contingent upon their parents' level of education.

Hypothesis four: Type of Institutions will not significantly influence students' environmental awareness knowledge.

Table 4. ANOVA table on Type of Institution and students' environmental awareness

\begin{tabular}{|l|l|l|l|l|l|}
\hline Source & $\begin{array}{l}\text { Sums of } \\
\text { Square }\end{array}$ & df & $\begin{array}{l}\text { Mean } \\
\text { Square }\end{array}$ & $\begin{array}{l}\text { F- } \\
\text { ratio }\end{array}$ & $\begin{array}{l}\text { Table } \\
\text { Value }\end{array}$ \\
\hline $\begin{array}{l}\text { Between } \\
\text { groups }\end{array}$ & 10.246 & 3 & 3.415 & & \\
$\begin{array}{l}\text { Within } \\
\text { groups }\end{array}$ & 1026.140 & 535 & 1.918 & 1.781 & 2.60 \\
\hline Total & 1036.386 & 538 & & & \\
\hline
\end{tabular}

Hypothesis four was test using ANOVA. (see Table 4). The calculated F-value was lesser than the table value. The result was not significant at 0.05 . Hence the hypothesis was accepted. Therefore type of Institution was not an important factor in students' environmental awareness knowledge.

Hypothesis five: Type of Institution will not significantly influence students' environmental attitude.

Table 5: ANOVA table on Type of Institution and students' environmental attitude

\begin{tabular}{|l|l|l|l|l|l|}
\hline Source & $\begin{array}{l}\text { Sums of } \\
\text { Square }\end{array}$ & df & $\begin{array}{l}\text { Mean } \\
\text { Square }\end{array}$ & $\begin{array}{l}\text { f- } \\
\text { ratio }\end{array}$ & $\begin{array}{l}\text { Table } \\
\text { Value }\end{array}$ \\
\hline $\begin{array}{l}\text { Between } \\
\text { groups }\end{array}$ & 9.343 & 3 & 3.114 & & \\
$\begin{array}{l}\text { Within } \\
\text { groups }\end{array}$ & 1787.566 & 535 & 3.341 & .932 & 2.60 \\
\hline Total & 1796.909 & 538 & & & \\
\hline
\end{tabular}

Hypothesis five was tested using ANOVA. The Fcalculated value was lesser than the table value. The result was not significant at 0.05 . The hypothesis was therefore accepted. Hence students' environmental attitude was not influenced by their institution of learning.

Hypothesis Six: There is no significant relationship between students' environmental awareness knowledge and their environmental attitude.

Table 6. Pearson Correlation Analysis on Relationship between students' environmental awareness knowledge and their environmental attitude

\begin{tabular}{|l|l|l|l|}
\hline & $\begin{array}{l}\text { Students' } \\
\text { environmental } \\
\text { awareness } \\
\text { knowledge }\end{array}$ & $\begin{array}{l}\text { Students' } \\
\text { environmental } \\
\text { attitude }\end{array}$ & $\begin{array}{l}\text { Table } \\
\text { Value }\end{array}$ \\
\hline $\begin{array}{l}\text { Students' } \\
\text { environmental } \\
\text { awareness } \\
\text { knowledge }\end{array}$ & 1.000 & .482 & .196 \\
\hline $\begin{array}{l}\text { Students' } \\
\text { environmental } \\
\text { attitude }\end{array}$ & .482 & 1.000 & \\
\hline
\end{tabular}

Hypothesis six was tested using Pearson product moment correlation method (see table 6). The rcalculated was greater than the table value. The result was found significant 0.05 level. The hypothesis was therefore rejected. Hence, there was a significant relationship between students' environmental awareness knowledge and their environmental attitude. In other words, students' attitude to their environment was related to their knowledge of environmental education.

\section{Discussion}

The study revealed that gender factor was not important in students' environmental awareness knowledge. The study further showed that gender of students was not an important factor in students' environmental attitude. This finding corroborated that of Akomolate [1], who found out that students' course of study significantly influenced their level of environmental awareness knowledge, and also their environmental attitude. Henderson et al. [7] corroborated this finding; he said that gender was not one of the top three factors related to environmental attitudinal outcomes. Gender issue might not have any impact on students; environmental awareness knowledge and also on students' environmental attitude because regardless of gender factor, students could have opportunity to have access to information 
on environmental education. However, Gambro and Switzky [5] suggested that gender was an influential factor in gaining environmental knowledge.

The result of this study showed that parents' level of education had no influence on students' environmental awareness knowledge. This study negates the finding of Akomolafe [1], that parents' educational background significantly influenced students' environmental attitude. She explained further that students whose parents possess higher education have more favourable environmental attitude. The finding of this study is contrary to expectation that parents should have more influence on their children education. It is believed that educated parents influence their children education positively. This study is also contrary to people's expectation about the role of education, in view of the suggestion of Westley-Shultz [15] that environmental concern are formed only when people see themselves as integral part of nature.

The finding of the study showed that types of Institution had no significant influence on students' environmental awareness knowledge. The study also found out that students' environment attitude was not influenced by the type of Institution. This study is similar to that of Olawepo and Jekayinfa [9] that teachers' attitudes and practices concerning environmental issue are significantly influenced by their area of specialization. The favourable disposition of students' to environment in terms of environment awareness knowledge and their environmental attitude cut across tertiary institutions (Akomolafe [1]. In other words, regardless of the type of tertiary institution, the level of environmental awareness knowledge and students' environmental attitude were similar. These institutions had various departments, in which students have responded positively and favourably to environmental issues. This point was buttressed by Akomolafe [1], while giving explanation on course of study's influence on student's level of environmental knowledge. She explained that the knowledge students acquired through education probably enhanced their level of awareness.

The finding of this study revealed that students' environmental awareness knowledge is related to their environmental attitude. This result might be due to the fact that the knowledge gained by students in the course of their exposure to environmental issue, constitute great influence on their attitude. This finding also supports the fact that education is a socializing process and a tool for enlightenment. The result of this study was corroborated by Arcury [2] that increased knowledge about environment is assumed to change environmental attitude.

\section{Conclusion and Recommendations}

Environmental issues and challenges have become a global concern. Environmental challenges coupled with the importance of education in bringing improvement to people's living in their interaction with the environment, constitutes a significant topical issue in the world. The significant positive correlation has been established between students' environmental awareness knowledge and their environmental attitude. It therefore confirmed the important role of education in meeting the challenges of environmental education. Gender, parents' education, type of institution, were not influential factors in students, environmental awareness knowledge. Furthermore gender and type of institution were not important factors in students' environmental attitude. This study thus, emphasized the need for environmental education to be intensified in tertiary institutions, and that its content should reflect the immediate needs of the students. Students, regardless of their gender, parents' educational background, and type of institution should be exposed to equal opportunity to learn, imbibe and acquire the knowledge and understanding of environmental education.

\section{References}

[1]Akomolafe, C.O., (2011), Environmental awareness knowledge and students' environmental attitude in tertiary institutions in Ekiti state. Canada International conference in Education (CICE-2011).

[2]Arcury T.A., (1990), Environmental Attitude and Environmental knowledge. Human organisation. Volume 49 No 4: pp300-304.

[3]Ben Elia N., (1980), "Environmental values and the Subjective Assessment of Residential Quality” Dissertation Abstracts International 41, 1) 433 A.

[4]Environmental Education (n.d) Defining Environmental Education. www.google.com (Access date: $14^{\text {th }}$ Oct.2010).

[5]Gambro and Switzky, (1994), cited in EETAP Resource Library (2000). Advancing Education and Environmental Literacy Number 92. www.google. Com (Access date: $15^{\text {th }}$ May 2011).

[6]Hatig, T; Kaiser, F.G and Bowler, P.A., (2001), Psychological restoration in nature as a positive motivation for ecological behaviour. Environment and Behaviour 33, 590-67.

[7]Henderson, D.G, Fisher D.L, Fraser B. J., (1998): Learning environment, student Attitudes, and Effects of students' sex and other science study in Environmental Sciences classes ERIC Documentation. Reproduction 
Service. (ED 420509) www.google.Com (Access date: $15^{\text {th }}$ May 2011).

[8]Kaplan, S. (2000). Human nature and environmentally responsive behaviour. Journal of Social issues (56) 3, 491508.

[9]Olawepo, J. A., and Jekayinfa, A. A., (1999): Assessment of the Environmental Attitudes and Practices of Teachers Undergoing Sandwich Degree Programmes in Nigeria. www.google.com (Access date: $14^{\text {th }}$ Oct. 2010).

[10]Pooley, J.A and O'connor, M (n.d) Environmental Education and Attitudes Emotions and Beliefs are what is needed. SAGEE Journals online http://eab.sagepub.com/content (Access date: $14^{\text {th }}$ Oct. 2010).

[11]Peer, S., Goldman, D., and Yavetz, B., (2007). Environmental literacy in teacher training: Attitude, knowledge, and environmental behaviour of beginning teachers. The journal of Environmental Education, (39)1 45-59

[12]Stern, P., (2000), Toward a coolant theory of environmentally significant behaviour. Journal of social issues, (56) 3, 407-424

[13]Stern, P. C., and Dietz, T., (1994), The value basis of environmental concern. Journal of social issues 50(3), 6584.

[14]Strapp W. B., et al., (1969), The concept of Environmental Education. Journal of Environmental Education 1 (1) 30-31.

[15]Wesley-Shultz, P., (2000), Empathizing with nature: The effects of perspective taken on concerns for environmental issues. Journal of social issues, (56) 3, 391406. 